\title{
A FIGURA FEMININA NA OBRA DO ALEIJADINHO.
}

\author{
JULITA SCARANO \\ Da Faculdade de Filosofia, Ciências e Letras de Rlo \\ Claro (Sáo Paulo).
}

Semelhante a todos os gênios, o Aleijadinho pode ser encarado pelos mais diversos ângulos, suscitando variadas reflexões. Às dúvidas e problemas sôbre a personalidade e a obra de Antônio Francisco Lisboa, o aspecto humano e artístico, ainda se soma o desconhecimento das reais condições da Minas Gerais do século XVIII.

Não que tais problemas tenham sido descurados e obras de fôlego e valor não existam, feitas por críticos de arte e historiadores de inteligência, cultura e sensibilidade, com verdadeiro espírito de aventura, nas piores condições possíveis, com imenso sacrifício e esfôrço. Mas nossos arquivos, ao que se sabe, são deficientes e falhos, muitos documentos, segundo consta, foram perdidos e mesmo as obras dos artistas se encontram muitas vềzes estragadas e dispersas.

O Aleijadinho, ponto alto da arquitetura e escultura não só brasileira, como americana, é igualmente figura popular. Ao lado de obras de eruditos, jornais e revistas de divulgação analisam sua vida e sua arte, sua doença e maneira de ser. Até mesmo dúvidas sôbre a existência do artista foram levantadas (1). De qualquer maneira, tôda a tentativa de estudo e interpretação tem o mérito de esclarecer dúvidas, levantar questões, abrir caminho para novas pesquisas que poderão clarear, sejam os problemas artísticos e culturais, sejam os históricos, sociológicos e econômicos da época.

Um aspecto curioso e que, parece-me, não foi devidamente levado em consideração é a pequena e mesmo insignificante quantidade de figuras femininas esculpidas por Antônio Francisco. Essa qua-

(1). - Augusto da Lima Júnior e outros, levantaram essa hipótese.

(2) - - Segundo Rodrigo Melo Franco de Andrade, em Ouro Preto, sấo de autoria do Alejjadinho as seguintes figuras femininas: a cabeça da imagem de Santa Helena da Igreja do Rosário, Nossa Senhora e o menino do Museu da Inconfidência, o lavabo em pedra sabão que representa Nossa Senhora do Carmo, na Igreja do mesmo nome, a Madona rodeada de anjos da 
se ausência da mulher na obra do toreuta pode ser exemplificada pelo pequeno número de esculturas de Nossa Senhora (2) .

Ora, no contexto do assim chamado barroco brasileiro, o da zona litorânea ou o dos morros auríferos das Gerais, a figura escultórica mais marcante é a de Maria. Reproduzida pelos artistas e santeiros em número elevadíssimo, a imagem de Nossa Senhora sempre ocupou posição preponderante nos altares das igrejas e nos oratórios particulares. Falando do orago das igrejas mineiras, Paulo Kruger Correia Mourão (3) diz que pelo menos oito igrejas matrizes tem o título de Nossa Senhora da Conceição. Essa invocação típica do espírito da Contra-Reforma, encontrou grande aceitação entre os paulistas, que a divulgaram pelos caninhos das Gerais. Aliás, a devoção à Maria acentuou-se no período, sendo um dos pontos discordantes entre protestantes e católicos, tendo grande aceitação na Europa ibérica e nos países católicos do Mediterrâneo até os dias de hoje, como demonstram Fátima, Montesserat, Lourdes, Pompéia e tantas outras. Na América espanhola e portuguêsa essa devoção chegou intacta, como atestam os numerosos centros de peregrinação. Em Minas, são também numerosas as igrejas dedicadas à bem portuguêsa Senhora da Piedade e também às patronas das inúmeras e atuantes Associações religiosas do século XVIII: à Nossa Senhora do Carmo, irmandade a que pertenciam os homens de prestígio, Nossa Senhora das Mercês, protetora dos mulatos, Nossa Senhora do Rosário, dos homens pretos, bem como outros títulos, ligados ou não às irmandades, como Nossa Senhora do Pilar, da Luz, das Dores, dos Prazeres, do O', do Bom Sucesso.

São muito mais freqüentes igrejas dedicadas à Nossa Senhora do que ao Senhor Bom Jesus e aos santos.

Também valorizavam-se as santas, como se nota pelo grande número de imagens, que não sendo orago de igrejas, ocupam papel preponderante nos altares laterais e nos oratórios particulares. Assim, Santa Ana, protetora das mães, era figura quase obrigatória e

Igreja de São Francisco de Assis. Na urna do altar-mór da mesma Igreja há uma cena das santas mulheres. Em Mariana há o célebre chafariz de Jesus e a Samaritana e encontramos cena semelhante em um dos púlpitos da Igreja do Carmo em Sabará, onde tambem notamos um rosto femenino no relêvo do "Avarento e seu tesouro". Na Matriz do Bom Sucesso de Caeté há uma Senhora do Carmo e em São João del Rel, na porta da Igreja do Carmo há a santa patrona da Irmandade e na Igreja de São Francisco de Assis, uma Imaculada Conceição. Uma Santa Ana ensinando Nossa Senhora, pertence à coleçấo Clerot. Além dessas, Germain Bazin considera obra do artista a Madona do Museu da Inconfidência de Ouro Preto, Madona do Rosário, e outra Santa Ana na coleção Leão Godin. Além dessas, outros críticos acrescentam ou tiram uma ou outra imagem.

(3) . - Mourăo (Paulo Kruger Correia), As Igrejas Setecentistas de Minas. BeloHorizonte, Editôra Itatiaia. 1964. 
Santa Bárbara, Santa Quitéria, Santa Efigênia são cultuadas em quase tôdas as cidades mineiras.

Levando em consideração a importância dêsse culto, é que nos parece insignificante o número de esculturas femininas executadas pelo Aleijadinho.

A avaliação numérica de suas obras vê-se complicada pelo critério utilizado no reconhecimento dessas obras. Se há autores que levam o rigor a ponto de só aceitarem de Antônio Francisco as que constam da documentação escrita, tão falha e fragmentária, a maioria segue o critério do estudo das características estéticas. A pesquisa técnica, meio comumente usado para o reconhecimento da paternidade artística, é a única possível num caso como o do Aleijadinho ou de outros artistas coloniais, uma vez que desapareceu em parte a documentação relativa às irmandades que encomendavam os trabaIhos e os recibos de particulares (4).

No caso específico de Antônio Francisco Lisboa, ainda vem sendo realizadas pesquisas em capelas e igrejas não devidamente estudadas ou em lugares onde êle esteve, segundo a tradição biográfica, mas êsses trabalhos ainda estão em andamento. As figuras que restam do belíssimo presépio do Museu da Inconfidência em Ouro Preto dão testemunho das obras perdidas. Nesse presépio, é evidente, deveria haver a Mãe do Menino, figura indispensável nas cenas da Natividade. Como essa Nossa Senhora dispersa e perdida outras Madonas ou santas devem ter desaparecido.

Mas, o desconhecimento do verdadeiro número de obras executadas pelo toreuta, não afeta profundamente a questão. Um estudo dos passos de Congonhas, nos faz ver claramente êsse problema.

Congonhas abriga o mais imponente conjunto criado por um artista nacional, caso único na história da América pós-colombiana, e é para André Malraux digno de fazer parte de um Musée Imaginaire (5), apesar de todos os êrros de anatomia mencionados por Eugênio Luís Mauro (6). Apesar das restrições que se possam imputar a um e outro dos profetas do Aleijadinho, estamos diante uma obra tão coerente e unida que nos dá a medida da capacidade arquitetônica do artista. Sentimos que, se a baleia ou o leão, êle os conhece apenas por leituras ou gravuras, o senso plástico do rítmo e das

(4). - Andrade (Rodrigo Melo Franco de), Contribuição para o Estudo da obra do Aleijadinho, in "Revista do Patrimônio Histórtco e Artístico Nacional". Rio de Janeiro, Imprensa Nacional Vol. 12, 1948. E' um relatório sôbre a documentação existente a respelto das obras do artista.

(5). - Malraux (André), La Statuaire. Le Musèe Imaginaire de la Sculpture Mondiale. Paris. La Galerie de la Pleiade, 1952.

(6) . - Mauro (Eugênto Luís), A Anatomia na obra de Aleijadinho. São Paulo, Editôra Anhambi, 1960 . 
relações entre uma figura e outra, entre as figuras do conjunto e a solidês das montanhas de ferro, agrestes, mas não agressivas da zona de Congonhas, se delinearam claramente em seu espírito e fizeram dos profetas uma obra sua, por mais que seus oficiais o tenham anxiliado na feitura de estátuas. Não estranha a ausência das profetizas de Israel no adro da Igreja do Senhor Bom Jesus de Matozinhos de Congonhas. Não são indispensáveis, antes, destoariam na severidade solene dos representantes da cultura patriarcal do povo eleito. Não caberiam no magnífico, terrível, grave e eterno "Colóquio das Estátuas" (7) .

Mas, em Congonhas, além dos profetas, encontramos os Passos. Nêsse numeroso grupo de 66 figuras, apenas três são mulheres. A desproporção dos números fala por si.

Inspirados nos santuários portuguêses da Paixão, que nossos artistas e santeiros tão bem conheciam pelos livros de devoção ou de gravuras, como também por tradição, os pequenos santuários para a comemoração das cerimônias litúrgicas da Semana Santa se espraiavam pelas povoações mineiras, assinalando com suas pequenas cruzes a piedade e o espírito religioso do período. As imagens, geralmente de roça, nas suas teatrais roupagens negras, rostos lívidos e mãos descarnadas, longas e sem consistência física, lembram EI Grecos sem corpos. A Virgem Dolorosa, poèticamente descrita por Murilo Mendes:

"Da vestimenta roxa emergindo mais branca,
$\ldots \ldots \ldots \ldots \ldots \ldots \ldots \ldots \ldots \ldots \ldots \ldots \ldots \ldots \ldots \ldots \ldots \ldots$
Um diadema de ouro a sua testa corôa,
Sete espadas mortais alimentam seu peito
Sete espadas mortais sustentam seu andar" (8)

é figura indispensável. Suas lágrimas, os cabelos negros e duros, o gesto sofredor, tem um apêlo dramático, caro ao período.

$\mathrm{Na}$ maioria das cidades mineiras, os Passos são pequenas capelas com santos de roça, abertos apenas durante a Semana Santa, quando as procissões litúrgicas iam de um a outro extremo da cidade, seguindo a Via Sacra. Em Congonhas, os Passos, de madeira, foram esculpidos pelo Aleijadinho e o Ataide, seu companheiro de muitos trabalhos, pintou-os. Trabalho dos dois maiores artistas plásticos da região, os Passos de Congonhas ocupam posição excepcional na inconografia brasileira e mesmo ibérica, em meio a tantos outros

(7). - Drumona de Andrade (Carlos), Colóquio das Etátuas, in "Passelos na Ilha". Rio de Janeiro. Editôra da Organizaçáo Simóes. 1952, pág. 57.

(8) . - Mendes (Murilo), Contemplaçāo de ouro Preto. Rio de Janeiro Imprensa Nacional, 1954. 
pobres, de roça e anônimos. Também, em Congonhas, as capelas não se distribuem pelo núcleo urbano, mas ocupam o jardim do morro onde foi construida a Igreja do Senhor Bom Jesus de Matozinhos e em cujo adro, severos, clamam os profetas.

A primeira das sete cenas abrigadas nas cinco capelas do jardim, é a Santa Ceia, ovalada, mais próxima como concepção da interpretação pré-leornardesca, onde as figuras dos apóstolos, ligadas plàsticamente umas às outras, vão convergir no Cristo que lhes promete o pão da vida. No Passo do Cristo no Horto, com o anjo barrocamente suspenso velando o sono de apóstolos que não puderam velar por uma hora, no da Flagelação, Coroação de espinhos e sobretudo na Crucificação isto é, nas sete cenas não encontramos a Virgem (9).

De Bretas (10), a Germain Bazin (11), os biógrafos acentuam a fé ardente e a importância do espírito religioso na elaboração da obra do Aleijadinho. O crítico francês assinala inclusive a grande importância que se dava no período à representação de Jesus sofredor e faz um estudo sôbre a maneira como os artistas encararam o assunto, desde o século XIII até a época barroca. Partindo de diferentes premissas, ora se acentua a Divindade do Cristo impassível, ora a Humanidade do Homem-Deus, expressando por meio da arte, seu pensamento religioso. Os espanhóis, mais do que os portuguêses e brasileiros, criaram muitos Cristos da Dor. Bazin acha mesmo que o Aleijadinho não se apoia nem em uns, nem em outros, mas com sua estilização gótica de Cristo e dos apóstolos, se aproxima mais dos artistas da primeira Renascença, dos escultores em madeira da Alemanha do século XVI.

Os Cristos flagelados, de punhos sanguinolentos, as mãos amarradas, as veias salientes, mostram a presença da agonia e da morte, tão explorados pelo barroco, tanto europeu como americano. Olhos longínqüos, corôa de espinho e a sugestão de sangue dos Cristos doloridos dos Passos, mostram a integração do Aleijadinho na sua época. Essa coexistência de elementos góticos ao lado de florões e cornucópias, nos mostram a ambigüidade dêsse artista e da arte mineira do período, utilizando soluções tão diferentes. Encontramos a mesma ambigüidade entre o pensamento e a ação dos inconfidentes.

\footnotetext{
(9). - Muitos autores consideram que pelo menos uma das mulheres representadas é Nossa Senhora. Altás, a maiorla apenas faz mençio ao assunto, sem entrar em detalhes.

(10): - Bretas (Rodrigo José Ferreira), Traços biográficos relativos ao finado Antônio Francisco Lisboa, mais conhecido pelo apelido de Aleijadinho in "Antônio Francisco Lisboa, o Aletjadinho". Rio de Janeiro. Publicaçóes da Diretoría do Património Histórico e Artístico Nacional, 1951. Vol. 15.

(11). - Bazin (Germain), Aleijadinho et la sculpture baroque au Bresil. Paris. Le Temps, 1966.
} 
Quanto ao elemento feninino, no Passo de Jesus carregando a Cruz há duas mulheres e mais outra no do Calvário. São criaturas do povo e tanto a que enxuga as lágrimas do rosto, como a que carrega o filho numa pose antinatural, ou a que ajoelhada ergue os braços de maneira dramática, não passam de comparsas ao drama da Paixão.

Enquanto Lourival Gomes Machado (12) considera que a figura feminina na cena da Crucificação representa Maria Madalena, Vitorino Nemésio fala da "Subida do Calvário com Nossa Senhora chorando como uma mulherinha do sertão" (13). Mesmo que não se concorde com o estudioso português e que êsse "chorando" pareça caber melhor à figura do outro Passo, a palavra "mulherinha" exprime bem a característica dessas figuras, que ocupam papel secundário e inferior, do mesmo modo que os soldados, trabalhados de maneira protesca e caricatural, possivelmente pelo atelier de Antônio Francisco.

E' pouco provável que êssa figura seja Nossa Senhora, uma vez que o toreuta não lhe deu o tratamento dignificante que caracteriza as figuras importantes dos diversos Passos e que deu à Madona em suas outras obras, como a do Lavabo do Carmo de Ouro Preto, por exemplo. Mesmo na pintura, não há o requinte encontrado nos "santos" de Congonhas, hoje valorizados pela restauração empreendida pela Diretoria do Patrimônio Histórico e Artístico Nacional.

Germain Bazin tem a respeito das figuras secundárias uma frase muito interessante:

"A Congonhas, par contraste, le caractère des ennemis du Christ, met en valeur cette beauté, qui n'est pas de ce monde. Un peuple de larves, de guignols et de gnomes-Celui des hommes - la "canaille" comme on l'appelle dans les roles de la'Passion chantées - s'agite autour de I'Intangibe, qui cependent n'est pas I'Impassible (...) (14).

Muitos outros estudiosos acentuam êsse aspecto de sêres abjetos, indignos da arte, atirados a uma espécie de inferno, criaturas à parte, diferindo de modo marcado e nítido dos "santos". Um rápido olhar a qualquer das duas cenas que contém mulheres, nos leva a classificá-las num grupo diferente do dos belos e requintados Cristos e apóstolos. Também, não atingem o ridículo dos soldados romanos, o inimigo, parecem pertencer a um mundo intermediário.

(12). - Machado (Lourival Gomes), Reconquista de Congonhas. Fotografias de Eduardo Ayrosa. Rio de Janeiro. Instituto Nacional do Livro. Ministério da Educação e Cultura, 1960.

(13) . - Nemésio (Vitorino), Os segrêdo de Ouro Preto e outros caminhos, Lisboa, Livraria Bertrand, s. d., pág. 298.

(14). - Bazin (Germain), op. cit., pág. 244. 
Nem exprimem a dignidade, a fôrça, a santidade de Cristo e dos apóstolos, nem se colocam entre os soldados. Não tem nobreza mas não pertencem inteiramente do conceito de canaille.

À objeção de que o artista da região trabalhava por encomendas, como de resto em diversas épocas e lugares, e que êste foi o caso do Aleijadinho, ousaríamos afirmar que no caso dos Passos, certamente não lhe foram impostas cenas e figuras. Em relação às encomendas, evidentemente muitas eram precisas e específicas, como o lavabo de Nossa Senhora do Carmo em Ouro Preto ou o de São Francisco de Assis, na mesma cidade. Quando Antônio Francisco executou essa encomenda era artista conhecido, aceito, bem pago. A concepção da obra é sua, criação de seu gênio e de sua fôrça. Também lhe pertencem tôdas as figuras, mesmo as que êle não esculpiu diretamente, as trabalhadas pelo seu atelier. Em qualquer delas notamos o nariz excessivamente longo e reto, os olhos arregalados, as lagrimais bem nítidas, a ligação entre as sombrancelhas, o queixo bipartido e o mesmo conceito anatômico da cabeça. Nas figuras da segunda plana, essas características foram grotescamente acentuadas.

Se nos Passos, é chocante a pouca importância dada à figura feminina, também notamos por exemplo a falta de uma Santa Clara, tão importante na iconografia franciscana, modelo para as irmãs terceiras. Essa quase ausência feminina nos leva a indagar: Qual teria sido o significado da figura da mulher na vida e na obra do artista?

Essas indagações não foram ainda devidamente levadas em consideração. Novas abordagens poderiam ser feitas, quer de caráter estético, reconhecimento e características, de suas obras, quer de caráter pessoal e psicológico, à maneira dos estudos de Freud sôbre Leonardo da Vinci (15) e mais recentemente os da Dra. Françoise Minkowska sôbre Van Gogh e outros artistas dessa época. A Dra. Minkowska, sobretudo em relação a Van Gogh usou várias fontes, mas deu ênfase ao estudo dos quadros do artista para sua interpretação (16) .

No caso do Aleijadinho, tal estudo seria incomparàvelmente mais difícil e possìvelmente falho, porque, com exceção de suas produções artísticas, nada de pessoal foi encontrado até o presente momento. De qualquer maneira, há material variado e abundante para permitir novas abordagens cheias de possibilidades. Quanto à biografia, os pesquisadores modernos, se bem que acrescentaram muitíssimo

(15). - Freud (Sigmund), Uma recordaçáo de infancia de Leonardo da Vinci. Rio de Janeiro, Editôra Delta S.A., s.d. Obras Completas. Vol. XI.

(16). - Minkowska (Françoise), Van Gogh, sa vie, sa maladie et son oeuvre. Paris. Presses du temps présent, 1963; Ibidem, De Van Gogh et Seurat aux dessins d'enfants. Gulde de l'Exposition au Musée Pedagogique. Paris, 1949 . 
ao conhecimento de sua arte e de sua época, não puderam deixar de se basear em Bretas (17), principal fonte para o conhecimento de sua vida.

Sem um trabalho de pesquisa completo e profundo, não se podem extrair conclusões. Elas seriam apenas apressadas e simplistas. Filho de um "distinto" arquiteto português e de mãe africana ou crioula, segundo nos conta Bretas, Antônio Francisco pertencia a um grupo bastante comum nas Minas Gerais do século XVIII. Consultando os registros de batizados da paróquia de Diamantina, encontramos um número eqüivalente ou superior de filhos ilegítimos sôbre os legítimos, a maioria dos quais, filhos de pretas ou mulatas, escravas ou forras (18). Nos outros lugares da região a situação era bàsicamente a mesma, uma vez que as mulheres brancas, no século XVIII eram pouco numerosas...

\footnotetext{
"em seus inícios e por muito tempo ainda, um povoamento predominantemente masculino: as mulheres são, de fato, comparativamente poucas em Minas, poucas e de baixa condição, quase sempre" (...) (19).
}

Filhos ilegítimos e mulatos eram a maioria dos artistas e dos músicos da região, era grande parte da população. Bretas e a maioria dos biográfos do Aleijadinho afirmam que mantinha boas relações com o pai, um de seus mestres no ofício de arquiteto. A questão do ensino profissional, dos artistas que o influenciaram e possibilitaram o pleno desenvolvimento de sua arte tem sido bastante estudado. Mas as relações pessoais entre o toreuta e seu pai ficaram nas sombras. Aliás, nenhum aspecto de suas relações familiares foi ainda sufficientemente explorado. A maioria dos pesquisadores dizem, por exemplo, que eram cordiais as relações entre Antônio Francisco e seus irmãos, mas Bazin discorda disso, alegando que se fôssem tão amigáveis, o artista não teria morrido na miséria e no abandôno, como afirma a tradição.

Ao que parece, a influência do pai deve ter sido significativa, uma vez que o Aleijadinho deu o nome de Manuel Francisco ao filho que teve da crioula fôrra Narcisa Rodrigues da Conceição, filho único ao que consta.

Seria interessante se, ao lado dos estudos a respeito da formação profissional do artista, de suas fontes, do conhecimento que ti-

(17). - Bretas (Rodrlgo José Ferreira), op. cit.

(18). - Pesquisas realizadas pela autora no Arquivo da Arquidiocese de Diamantina (Minas Gerais).

(19). - Holanda (Sérglo Buarque de), Metais e Pearas Preciosas in "História Geral da Civilização Brasileira. Vol. II. São Paulo. Difusão Européla do Livro, pág. 300 . 
nha a respeito das obras de arte européias e nacionais, fôsse feito um levantamento sôbre sua vida pessoal e familiar que poderia confirmar ou afastar as lendas que o cercam. Como aliás vem sendo feito a respeito da doença que originou a alcunha. A fantasia das histórias relatadas por Bretas parece ter marcado de tal modo a vida de Antônio Francisco que dificulta um conhecimento real de sua personalidade.

Além do aspecto pessoal e psicológico, um estudo social detalhado e especializado sôbre a posição da mulher na Minas colonial também daria uma contribuição esclarecedora a respeito do pequeno papel da mulher na obra do toreuta. Muito já foi realizado, mas ainda há aspectos não suficientemente esclarecidos. Os historiadores acentuam a pequena quantidade de mulheres brancas, mas isso não significa, entretanto, que elas ocupassem uma posição de primeira plana, ou tivessem voz a seu próprio respeito. As histórias numerosas da prepotência de pais e de maridos, ilustram bem uma situação que a Inocência de Taunay retrata, mostrando a persistência dessa reclusão e subordinação, que não se restringe nem ao século XVIII, nem à zona de mineração.

As "mulheres erradas", mulatas ou negras em sua maioria, numerosíssimas pela própria condição da sociedade colonial escravocrata, assim como as escravas, raramente alcançaram o prestígio e a fama de uma Chica da Silva e pouquíssimas outras, famosas justamente por terem galgado posição incomum. Não passavam de propriedade do homem branco, sofrendo freqüentemente perseguição das autoridades.

Mas, a licença de costumes era vista como normal pelo regime escravagista, o que escandalisou visitantes e estrangeiros e autoridades que vieram ao Brasil. As zonas de mineração eram centros dos mais agitados e promíscuos, pela preponderância do elemento masculino e pelo acúmulo de tantos aventureiros. Na época do Aleijadinho, essa situação ainda persistia em grande parte, acrescida de novos defeitos, segundo o autor das Cartas Chilenas, uma vez que a transformação sociais se processa lentamente. A escassez de metais preciosos ainda não trouxera uma sociedade nova.

Fecundo e interessante, seria também um estudo a respeito das mulheres artistas. Em Minas Gerais, não encontramos seus nomes nas fôlhas de contratação ou de pagamento feitos pelas irmandades. Aliás, essa ausência não é característica apenas brasileira, uma vez que sòmente o romantismo trouxe a moda de mulheres artistas, principalmente em relação às plásticas. Quanto à literatura, estudos recentes têm trazido à luz uma autora ou outra. Em Minas, com exceção de Bárbara Heliodora e poucas poetisas, não se conhece nin- 
guém. Em Diamantina (20), consta dos livros das irmandades o nome de uma organista, com o esclarecimento de que ela era cega, como a querer justificar contratação tão fora do comum .

Artista ou não, desde a Venus de Brassempouy, a mulher foi insiparadora da arte. Atenas ou Diana, Maria, mãe do Salvador, santa ou dançarina, sempre serviu de tema aos artistas, em épocas ou latitudes as mais diversas.

No século XVIII, em Minas e em outros recantos do Brasil era especialmente fecundo o papel de Nossa Senhora como tema artístico. Quase podemos dizer que era o assunto principal de artistas e santeiros, o que encontrava maior procura, tanto para decorar altares, tetos e paredes das igrejas, como para servir à devoção de particulares.

Também na literatura da época é importantíssimo o papel da musa feminina e na mesma região do Aleijadinho encontramos Marília e Glaura, inspirando poetas. O Aleijadinho é realmente exceção em seu ambiente.

Muitos aspectos interessantes do nosso maior artista plástico estão a pedir novas abordagens que nos levariam a conhecer mais profundamente aquêle que não impressionou seus contemporâneos, fôssem êsses habitantes da região ou visitantes estrangeiros, constatação que deixaram à sensibilidade dos pósteros.

(20). - Segundo informação do senhor Assis Alves Horta, funcionário do Patrimônio Histórico e Artístico Nacional (Diamantina, Minas Gerais). 